Abstracta Iranica Abstranica

Revue bibliographique pour le domaine irano-aryen

Volume 30 | 2010

Comptes rendus des publications de 2007

\title{
Rostam. Tales of Love \& War from Persia's Book of Kings. Translated by Dick Davis, Washington D.C., Mage Publishers, 2007, XXV+291 p.
}

\section{Christine Van Ruymbeke}

\section{(2) OpenEdition}

1 Journals

\section{Édition électronique}

URL : http://journals.openedition.org/abstractairanica/38007

DOI : 10.4000/abstractairanica.38007

ISSN : 1961-960X

Éditeur :

CNRS (UMR 7528 Mondes iraniens et indiens), Éditions de l'IFRI

\section{Édition imprimée}

Date de publication : 8 avril 2010

ISSN : 0240-8910

\section{Référence électronique}

Christine Van Ruymbeke, "Rostam. Tales of Love \& War from Persia's Book of Kings. Translated by Dick Davis, Washington D.C., Mage Publishers, 2007, XXV+291 p. », Abstracta Iranica [En ligne], Volume 30 2010, document 258, mis en ligne le 08 avril 2010, consulté le 26 septembre 2020. URL : http:// journals.openedition.org/abstractairanica/38007 ; DOI : https://doi.org/10.4000/abstractairanica. 38007

Ce document a été généré automatiquement le 26 septembre 2020.

Tous droits réservés 


\title{
Rostam. Tales of Love \& War from Persia's Book of Kings. Translated by Dick Davis, Washington D.C., Mage Publishers, 2007, XXV+291 p.
}

\author{
Christine Van Ruymbeke
}

1 Ce petit volume s'ouvre sur une introduction forte intéressante par le traducteur Dick Davis, illustrée par des reproductions tirées de deux lithographies du Šāh-nāme datant du milieu du XIXe siècle. Comme dans d'autres traductions offertes par Davis, le texte en prose restitue le contenu et les images poétiques du texte du Šāh-nāme, entrecoupé ici et là par des traductions versifiées de passages auxquels le traducteur désirait donner un relief particulier. Le contenu est présenté sous forme de dix-sept chapitres qui retracent la vie et les aventures principales du personnage shahnaméen Rostam. Le volume se termine par un index de tous les épisodes contenus dans les chapitres, suivi d'une brève description des illustrations.

2 La qualité du travail de traduction que Davis mène depuis de nombreuses années sur le Šāh-nāme est bien connue du public iranologue académique ou dilettante. Une traduction complète du Šāh-nāme (proposant avec le succès que l'on connaît, ce même patron de traduction en prose entrecoupée de passages en vers) est parue il y a quelques années en trois volumes chez le même éditeur et Davis nous a livré aussi les résultats de quelques recherches sur les thèmes principaux de l'œuvre de Ferdowsī. Avec cette nouvelle parution dédiée à Rostam, cet « Hercule Persan », Davis ne propose rien de neuf, sinon une collection en un volume des aventures de celui qui est considéré comme le héros principal du Šāh-nāme. Les spécialistes de l'œuvre de Ferdowsī sont d'accord pour qualifier le cycle sistanien, contant les aventures de la famille de Rostam, comme une œuvre séparée qui fut incluse à une date reculée dans le Livre des Rois. L'on pourrait considérer que Davis recrée en quelque sorte ce cycle. Mais, outre le fait qu'il n'a probablement pas cherché à faire ceci, l'on doit de plus admettre que ce cycle des aventures de la famille de Zāl et Rostam ne peut plus être séparé, tant leurs fils 
s'entrecroisent dans la trame du récit, de la dynamique de l'histoire des shahs d'Iran. Ainsi, le public auquel ce volume semble s'adresser, serait plutôt à considérer comme un public large et non-académique désireux de connaître les aventures du fameux Rostam, abstraction faite de l'immense volume du «cadre » shahnaméen dans lequel elles apparaissent.

INDEX

Thèmes : 11.1.1. Littérature persane classique

\section{AUTEURS}

CHRISTINE VAN RUYMBEKE

University of Cambridge 